\section{Espacios públicos precordilleranos \\ Camino a Farellones, Chile}

En la precordillera de Santiago, en la abrupta subida al centro de esquí Farellones, se proyectan espacios públicos que proponen inyectar actividades de turismo y recreación en zonas poco valoradas. Ambos se estructuran en base a paseos -en relación con las bajadas de agua o nieve-, zonas de observación y áreas de esparcimiento.
In the foothills of Santiago, in the abrupt ascent to the Farrellones ski center, public spaces have been designed that propose the injection of turist activities and recreation in under-valued zones. Both are structured around the base of outings -in relation to the the descents of water or snow- observation zones and recreation areas.

Catalina Picon Arquitecta, Pontificia Universidad Católica de Chile

Bernardita de Iruarrizaga Arquitecta, Pontificia Universidad Católica de Chile

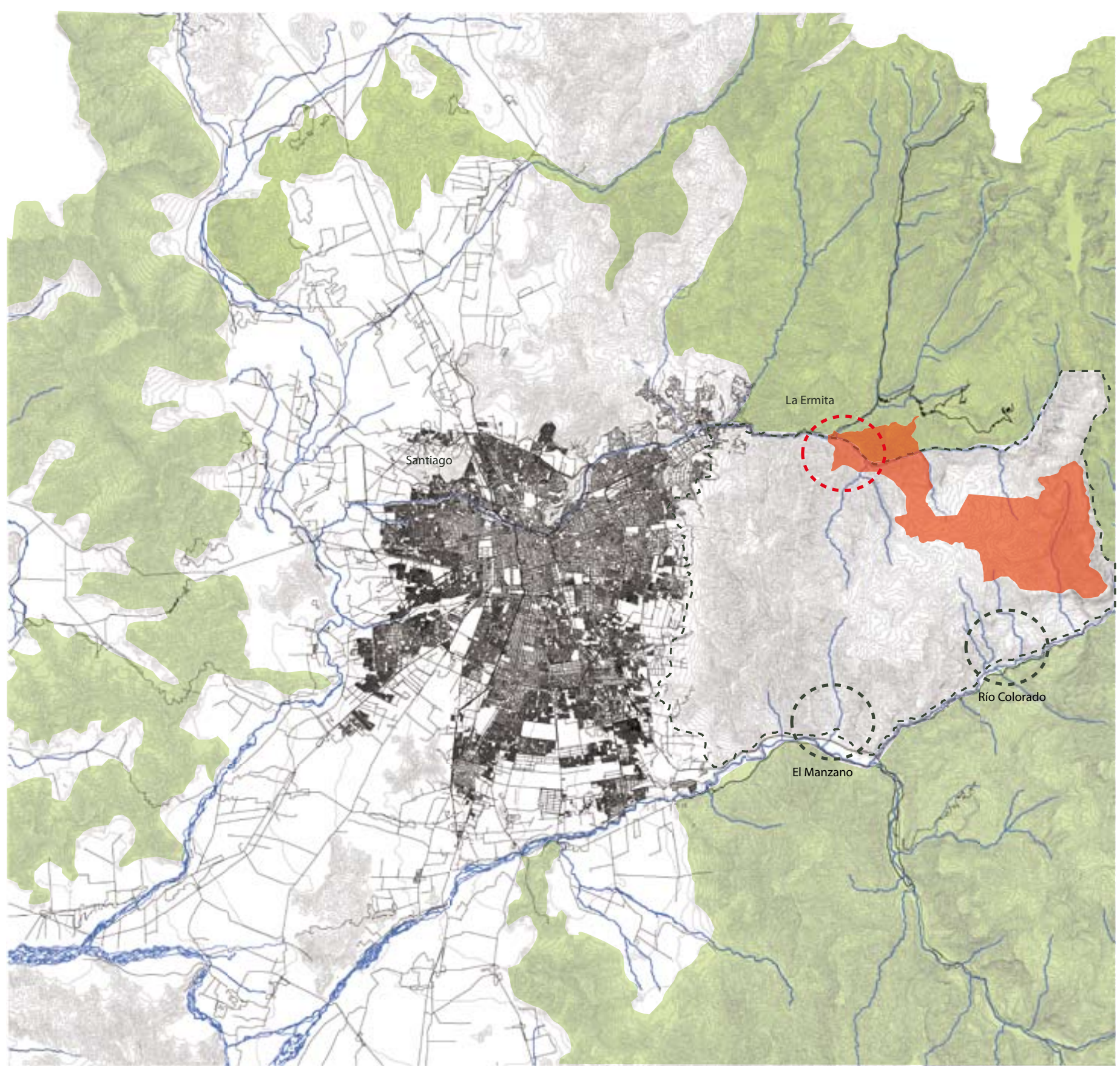

Localización proyectos La Ermita y Farellones, Región Metropolitana, Chile. Fuente: elaboración de las autoras

- 
1 Es importante mencionar que gran parte de la información sobre debido a la inexistencia de planos, fotografías e información suficiente para el estudio del área y la elaboración de un proyecto de estas características.
"Los visitantes perciben la precordillera de Santiago como un paisaje deteriorado, debido a la expansión urbana. Concuerdan en que es importante generar una relación armoniosa entre la ciudad y su entorno natural, a través de una ordenación coherente del paisaje; como crear programas de educación ambiental para que la gente conozca y proteja este ecosistema." (De la Fuente, Mühlhauser, 2006)
Santiago no es una ciudad que se destaque por tener gran cantidad de áreas verdes ni espacios públicos. Al contrario, debido a su crecimiento de manera expansiva al desarrollo de urbanizaciones tipo ciudad jardín, la iniciativa de creación de espacios verdes públicos se ha dejado de lado, perdiéndose la relación con el entorno, la naturaleza autóctona y la geografía circundante.

La cordillera de los Andes es un hito geográfico esencial en la identidad de Santiago. En ella se encuentran algunos de los centros de esquí más importantes del cono sur: Farellones, Valle Nevado, La Parva y El Colorado. A ellos se accede a través de la cuenca del río Mapocho por un camino de 30,8 kmruta G21-, desde Lo Barnechea a $859 \mathrm{msnm}$ hasta Farellones a $2.360 \mathrm{msnm}$. Este camino se localiza en un escenario natural de enorme potencial paisajístico, turístico, deportivo y recreacional que hasta el momento no se ha sabido aprovechar. Hoy es sólo una zona de traspaso entre la ciudad y la alta montaña, un camino que se utiliza sólo en invierno para acceder a los centros de esquí. Desde 1939 -año en que se terminó de construir- hasta la fecha, no se le ha realizado ninguna modificación significativa, a pesar de las malas condiciones y las deficiencias de seguridad que presenta. Casi tres mil autos suben en la temporada invernal, lo que impide un buen desarrollo y ocupación de las áreas aledañas a la ruta, por falta de infraestructura e instalaciones.

El proyecto propuesto busca revalorizar el paisaje del camino a Farellones, rescatando su carácter de pulmón verde y recuperando esta zona como un área de esparcimiento y turismo. Se plantea una solución integral que une naturaleza, paisajismo, arquitectura y vialidad como un sólo proyecto. $\mathrm{Al}$ hacerse una real inversión en el camino se logra una mejoría de la zona, pues no es solo un arreglo vial. Para esto se definieron tres capas de proyecto; una primera dimensión longitudinal de paso para el auto y la bicicleta, utilizada para acceder a los centros de esquí o simplemente como un recorrido para hacer deporte; una dimensión transversal turística y recreativa que es la que transforma el camino de un lugar de paso a un lugar de estar y por último una dimensión transversal que es espina dorsal del proyecto, unificando las dos dimensiones anteriores y otorgando seguridad a los habitantes de la zona. Como estrategia se definieron cuatro elementos de intervención: circulaciones -ruta vehicular, la espina dorsal, ciclovías, senderos, paseos peatonales y estacionamientos-, vegetación -reforestación del camino, protegiendo los cortes del cerro y acompañando a la ruta de manera intencionada-, aguas - puntos del río donde se generan pozones naturales y playas- y una capa de programas que une los existentes con nuevos a incorporar, otorgándoles las instalaciones y accesos necesarios para mantener un buen desarrollo y un constante flujo.

Se definen dos principales focos de desarrollo dentro del camino: la zona de La Ermita y el pueblo de Farellones, por su ubicación estratégica y características excepcionales.

PROYECTO LA ERMITA / Tiene por objetivo la apertura y recolonización de un espacio en la pre-cordillera por medio de la revalorización del paisaje y potencialidades de la zona como área de esparcimiento, turismo y educación, creando un nuevo destino turístico en el camino a Farellones.

Se clasifican tres tipos de paisajes al momento de enfrentar el lugar y el entorno que conforman: paisaje cultural -conocimiento arriero, religioso y turístico-, paisaje productivo -actividades agrícolas y ganaderas-y paisaje natural -reforestación y restauración de la flora nativa-. La clasificación y superposición de estos tres paisajes, a modo de capas de intervención, es lo que finalmente conforma el masterplan del proyecto. Basado en esto se desarrollan 3 zonas de traspaso hacia el interior cordillerano:

La Ermita: entrada hacia la cordillera donde se recibe a los turistas que visitan el lugar. Se establece como base para conocer e internarse en el valle, recibiendo al mismo tiempo a los turista que van de paso.

Media luna: contiene los programas necesarios para el funcionamiento del fundo. Se rescata lo que existe, proporcionando actividades turísticas que generen ingresos para el mantenimiento del lugar.

La Junta: Está orientado para los que buscan tener mayor relación con la naturaleza: la vegetación, el agua y las vistas panorámicas.

PLAN INTEGRAL DE ESPACIO PÚBLICO PARA FARELLONES / Busca CONsolidar este centro como pueblo de montaña para que sea utilizado durante todo el año, aprovechando su condición final de la ruta G21 y de paso obligado a los centros de esquí y así establecerlo como nodo de servicios y esparcimiento.

El proyecto busca generar espacios públicos que permitan un mejor aprovechamiento de los recursos y paisajes de Farellones, así como conexiones eficientes y seguras que otorguen un mayor valor a su centro, potenciando y evidenciando las características propias del lugar.

El plan consiste básicamente en tres intervenciones principales que conectan el pueblo completo, generando una red de espacios públicos funcionales y sustentables. La primera genera un parque en la ex cancha La Gran Bajada, que actúa como eje principal de Farellones estimulando el uso del espacio público. Se constituye como un parque de educación ambiental con árboles, pastos y hierbas nativas. La segunda intervención es la consolidación de un boulevard de recreación en el sector Novicios, donde se establece una zona de comercio, restaurantes, paseos peatonales, estacionamientos y acceso a las canchas de esquí. La tercera y última es la proyección de un recorrido de cornisa que rodea Farellones. Este recorrido está acompañado de un parque de borde que hacia el sur actúa como cortavientos y hacia el norte busca reforestar, sostener las pendientes, combatir la erosión existente y exhibir la vegetación nativa de Farellones.

Todas estas intervenciones se unifican entre sí y con el pueblo mediante un sistema de circulaciones transversales para peatones y esquiadores, acompañada de un escurrimiento superficial de aguas lluvia, que genera un sistema de franjas verdes inundables con vegetación nativa y otras especies propuestas. ARQ

\section{Bibliografía}

De la Fuente, Gonzalo y Hermann Mühlhauser. Precordillera Andina de Santiago. Percepciones, actitudes y preferencia en visitantes urbanos. Universidad del Bío Bío, Concepción, mayo de 2006. 

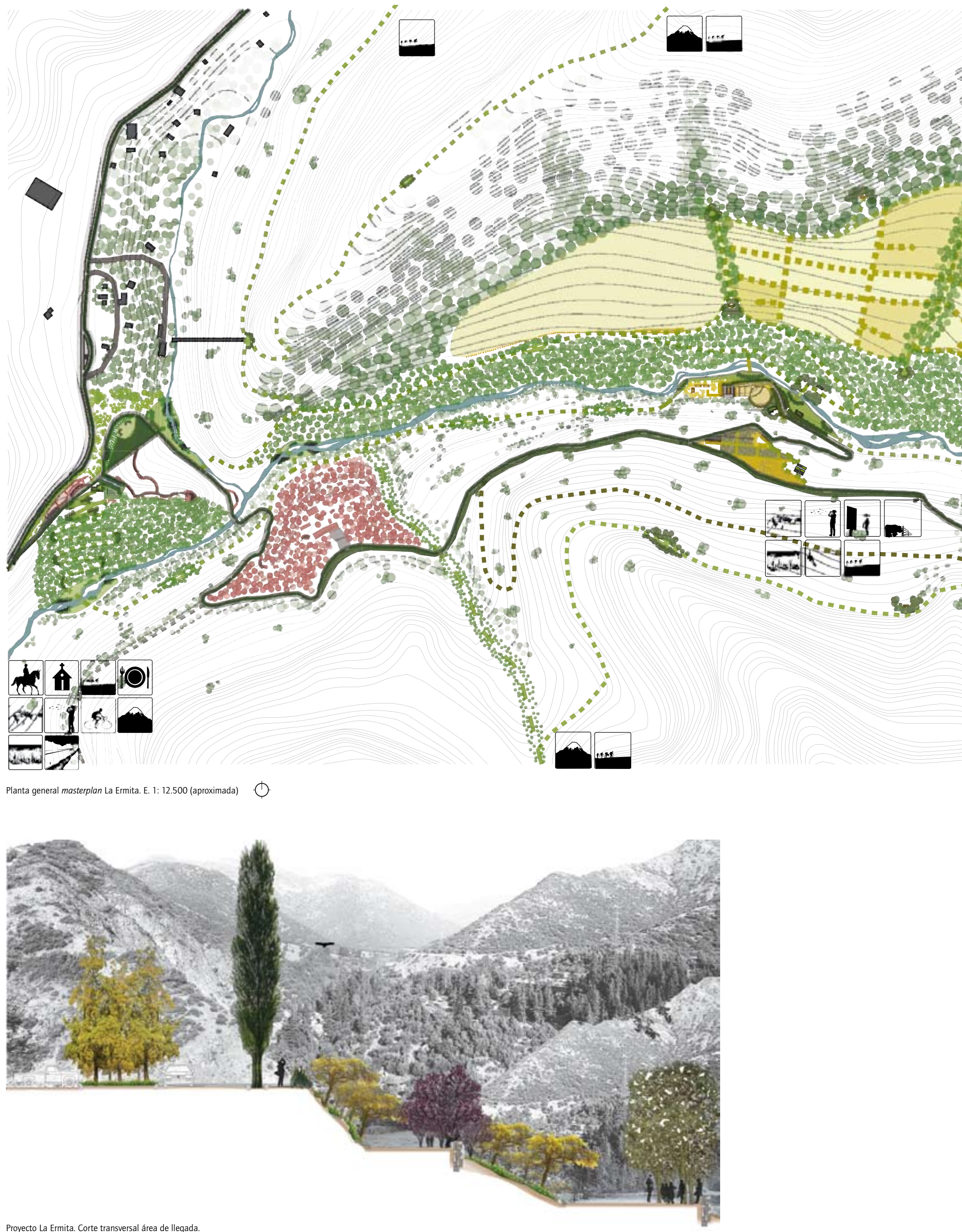


\section{C.}

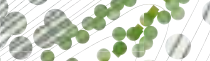

1000.83507

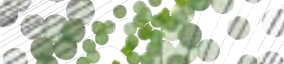

25.390

is

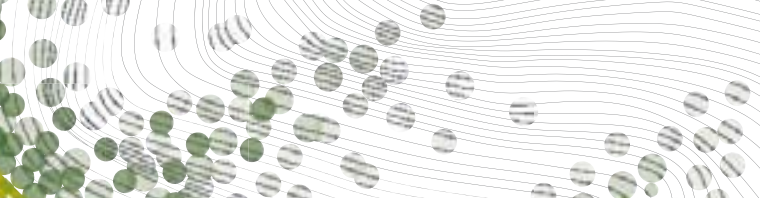

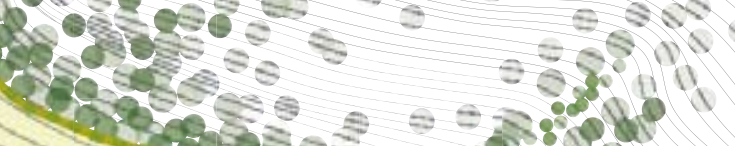

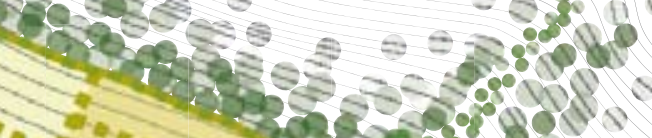

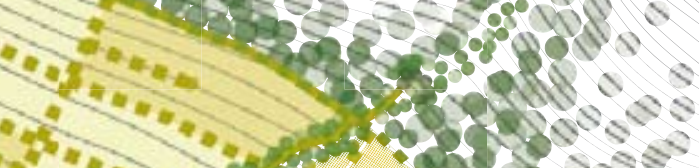

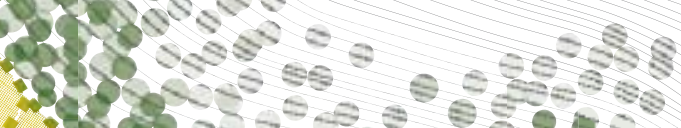

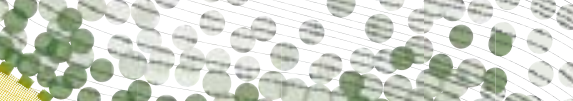

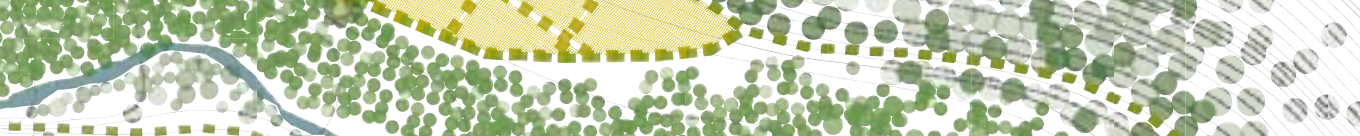

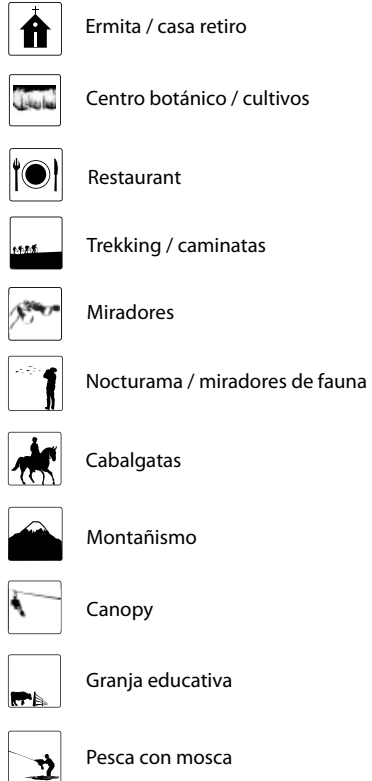

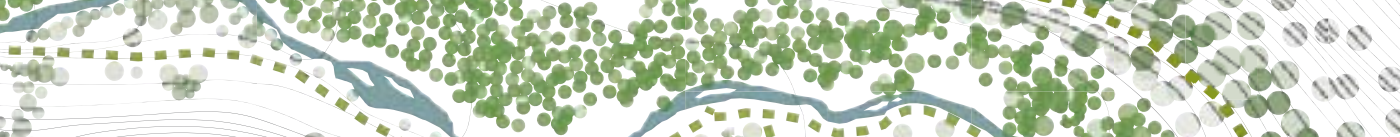

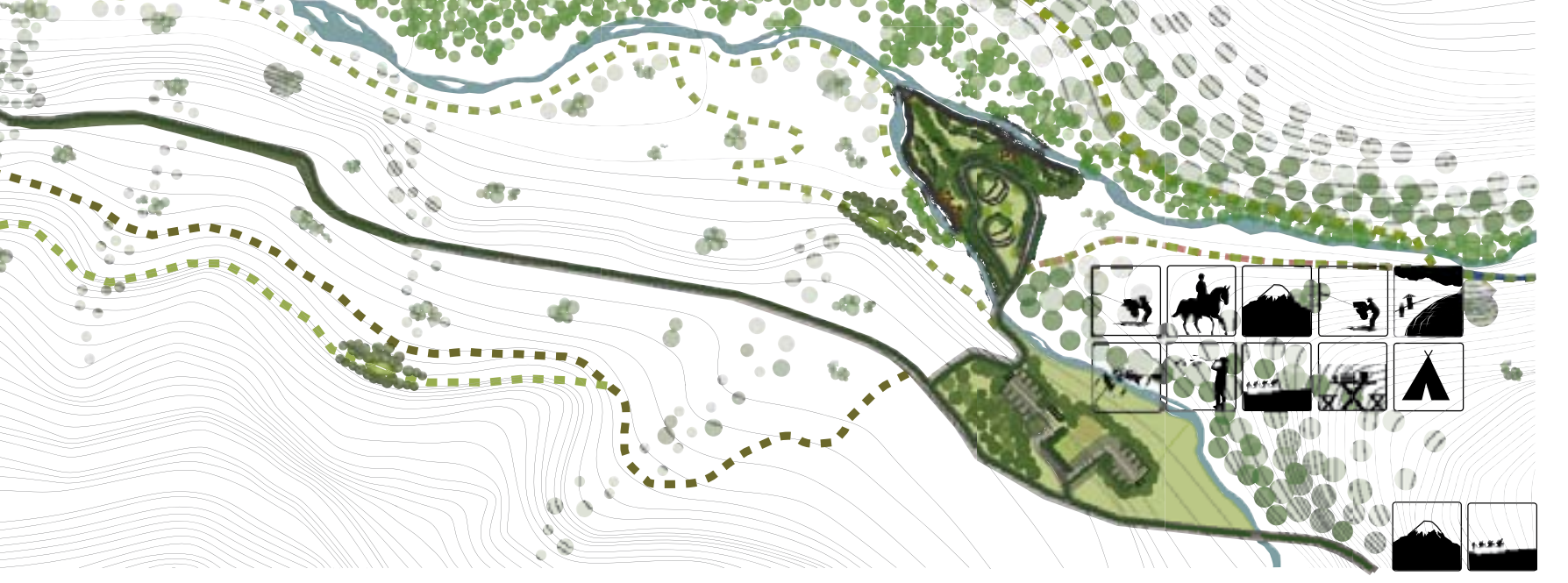

A Camping

7 Pozones

发 Picnic

rí
camino farellones
camino vehicular
ciclovia

edificaciones existe

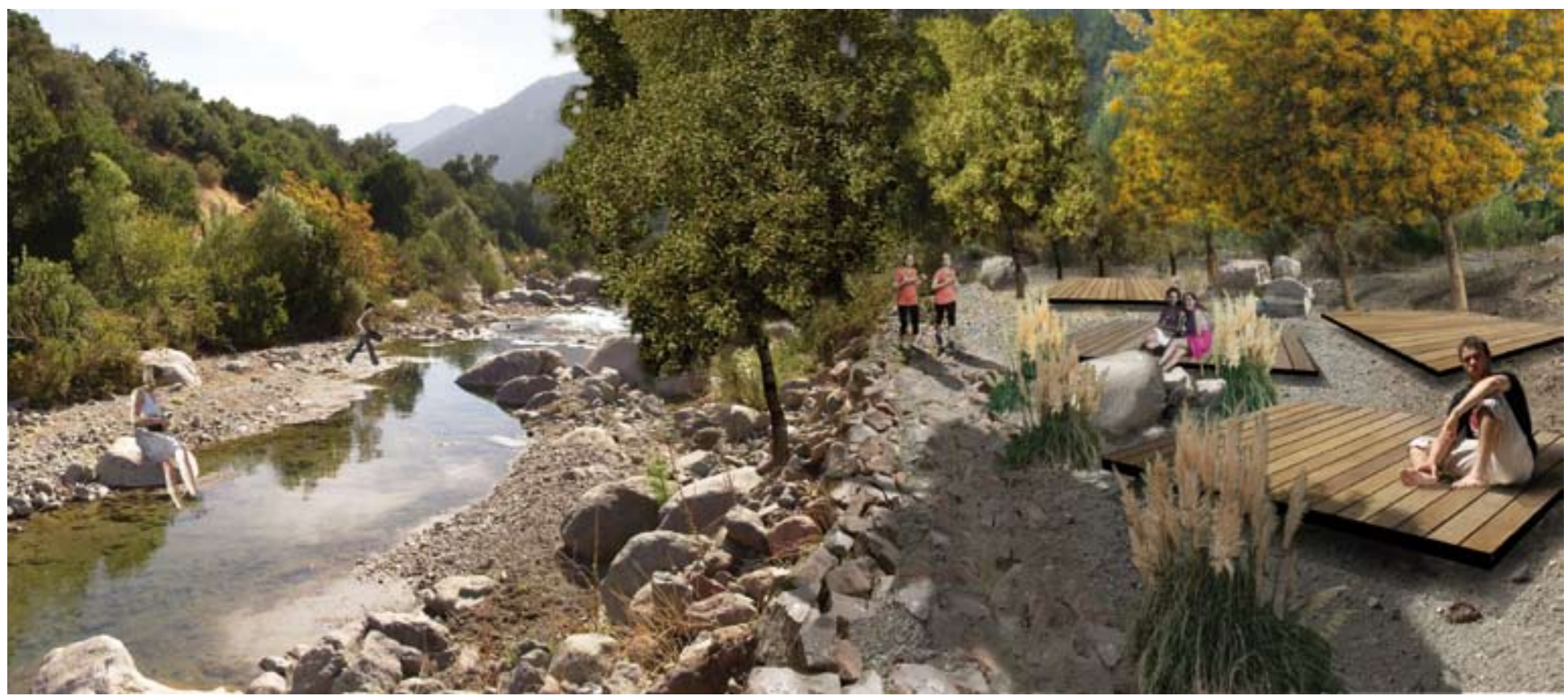

Proyecto La Ermita. Pozón La Junta 


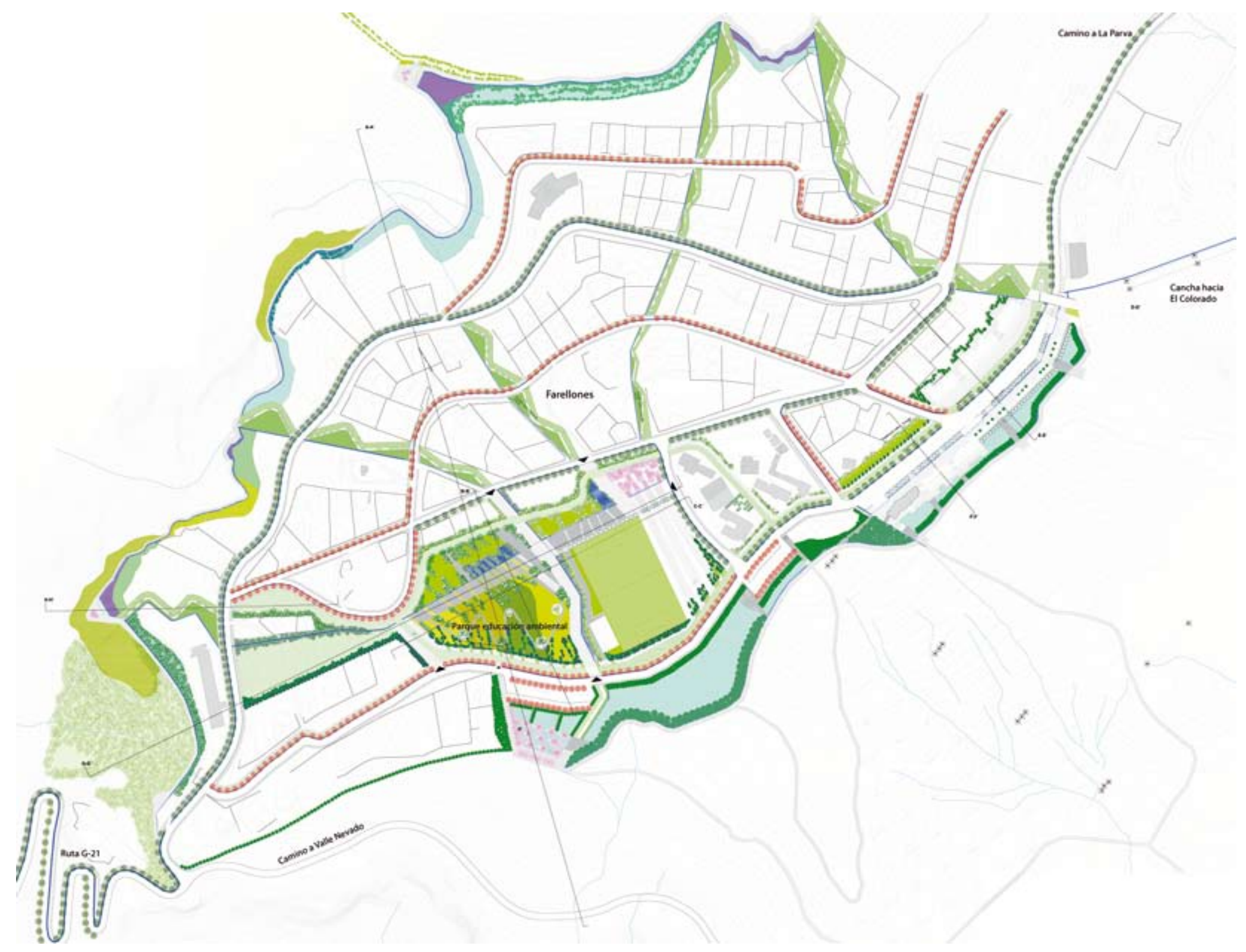

Planta general masterplan Farellones. E. 1:2.500

\begin{tabular}{l}
\hline Camino pavimentado \\
Camino de tierra \\
Pavimento de piedras rústicas en boulevard de comercio, restaurantes y parque \\
Recorrido de cornisa y paseo de borde sur \\
Recorrido peatonal de gravilla \\
\hline Equipamiento comercial y gastronómico proyectado \\
\hline Escurrimiento de aguas \\
\hline Drenaje existente \\
\hline Linea de pasto para crecimiento de arboles de borde \\
\hline Parque propuesto, zonas de pasto \\
\hline Pasto nativo 1: dedal de oro \\
\hline Pasto nativo 2: Piretro de jardin \\
\hline Pasto nativo 3: Hierba blanca \\
Pasto nativo 4: Capachitos rojos \\
Bajadas de esquiadores propuestas, cubresuelo \\
Humedales o vegas: quiaca y hierba del chancho
\end{tabular}

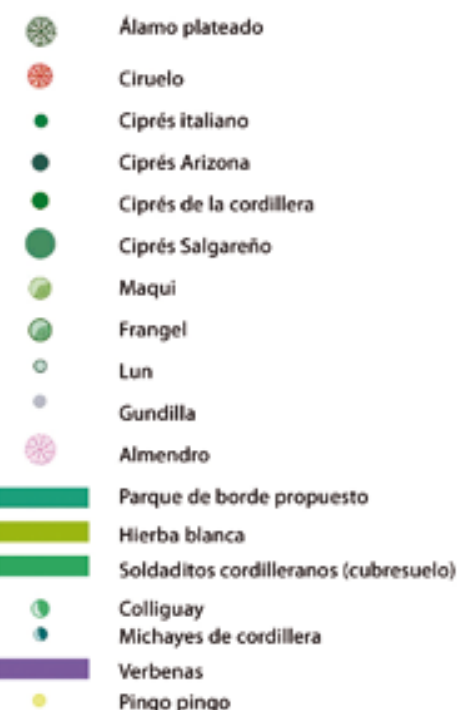


